\title{
Resenhas
}

\section{Repensando causalidade, complexidade e evidência para o paciente singular: um recurso do projeto CauseHealth para os profissionais de saúde e o encontro clínico}

Rethinking causality, complexity and evidence for the unique patient: a CauseHealth resource for healthcare professionals and the clinical encounter

Repensar la causalidad, la complejidad y la evidencia para el paciente único: un recurso del proyecto CauseHealth para los profesionales de la salud y el encuentro clínico

\author{
Alberto 0. Cupani(a) \\ <cupani.alberto@gmail.com> iD \\ Charles Dalcanale Tesser ${ }^{(b)}$ \\ $<$ charles.tesser@ufsc.br> iD
}

Esta obra ${ }^{1}$ (que está disponível em acesso aberto na internet no endereço https://link.springer.com/book/10.1007\% 2F978-3-030-41239-5) nos parece uma grande contribuição de um projeto interdisciplinar norueguês liderado por filósofos e desenvolvido com a participação de clínicos de várias profissóes e países, que elucida com disciplina, clareza conceitual e didatismo raros as características das concepçôes causais correntes na saúde baseada em evidências e seus desdobramentos na construção do saber clínico e nas práticas de cuidado. Mais do que oferecer uma crítica ao famigerado e de muito tempo criticado modelo biomédico, o livro oferece uma base filosófica distinta, o disposicionalismo, como uma plataforma pela qual, defendem os autores, pode ser construída e disseminada uma abordagem científica da saúde-doença que supere algumas limitações do saber e das práticas clínicas contemporâneas, geradoras de frustrações que não cessam de crescer.

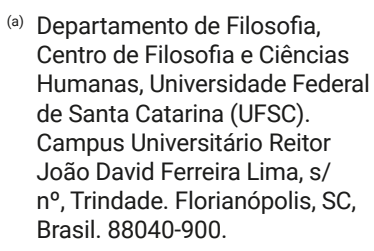

(a) Departamento de Filosofia, Centro de Filosofia e Ciências Humanas, Universidade Federal de Santa Catarina (UFSC). Campus Universitário Reitor João David Ferreira Lima, s/ $\mathrm{n}^{\circ}$, Trindade. Florianópolis, SC, Brasil. 88040-900.

continua pág. 07

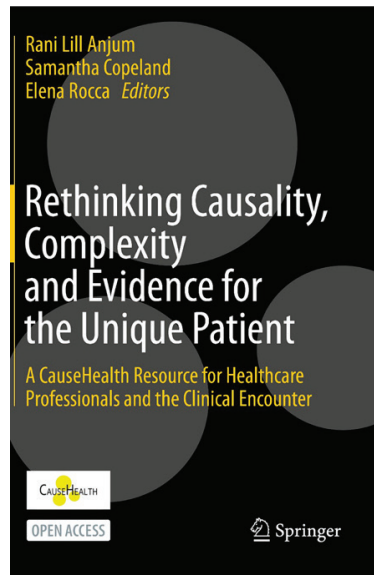

Anjum RL, Copeland S, Rocca E. Rethinking causality, complexity and evidence for the unique patient: a CauseHealth resource for healthcare professionals and the clinical encounter. Cham, Switzerland: Springer; 2020. https://doi.org/10.1007/978-3030-41239-5 
Na primeira parte do livro, intitulada "Marco Filosófico" (Philosopbical Framework), os autores defendem a importância de detectar os pressupostos ontológicos (isto é, relativos ao ser das coisas), epistemológicos (relativos ao conhecimento, particularmente aos métodos) e normativos (referentes à prática) das profissões relacionadas com o cuidado da saúde. Isso porque tais pressupostos influenciam todos os aspectos dessas profissões: "Eles enviesam em direções específicas o desenvolvimento de hipóteses, o design de experimentos, a avaliação da evidência e a interpretação de resultados”' (p. 3).

Por conseguinte - alegam -, se queremos produzir uma mudança nas práticas relativas ao cuidado da saúde, não podemos deixar intocados esses pressupostos, porque, por exemplo, a intenção de fornecer um cuidado integral, que aborde não somente o aspecto biológico do paciente, mas também as dimensóes biográfica, social e cultural da sua existência, fica contrariada ao pressupor o dualismo cartesiano almacorpo (uma suposição ontológica).

O interesse pelo background filosófico data da introdução da "Medicina Baseada em Evidências” (MBE) na década de 1990 - informam os autores - do qual seriam testemunhas movimentos como a "Medicina e a Prática Centralizadas na Pessoa" [Person Centered Medicine and Practice], a "Campanha por uma Medicina Baseada em Reais Evidências” [Campaign for Real Evidence Based Medicine] e a "Rede de Fisioterapia Crítica" [Critical Physiotherapy Network]. Tais movimentos críticos focaram aspectos básicos da prática profissional no que tange a seus fundamentos ontológicos, tais como o modelo biomédico, a fragmentação do cuidado e a chamada medicalização da vida. No plano metodológico, as críticas recaíram sobre a insuficiência de procedimentos e recursos puramente técnicos (como o emprego de evidências produzidas estatisticamente e a causalidade estabelecida randomicamente) para entender o paciente na sua singularidade; especialmente para abordar quadros que envolvem fatores psicológicos tais como estresse e trauma. Igualmente questionáveis se tornaram os limites da validade externa (clínica) dos resultados de experimentos estritamente controlados. Já quanto à prática, as vozes críticas reivindicaram a importância do juízo clínico (experiência) versus o uso demasiado confiante das evidências científicas, e censuraram a medicina baseada na eficiência, que se serve de padróes genéricos (como diagnósticos-padrão) e lhe opóe uma medicina centralizada nas necessidades do indivíduo.

O livro, definem os autores, "é um instrumento para entender algumas das motivaçóes filosóficas e a racionalidade por trás da maneira como a medicina e o cuidado da saúde são estudados, avaliados e praticados, na interface da ciência e das humanidades”1 (p. 7). Eles querem mostrar como uma mudança nas convicçôes ontológicas poderá trazer uma "mudança de paradigma" tanto na pesquisa como na prática profissional.

Em particular, querem mostrar o impacto que uma outra maneira de pensar a causalidade das doenças e dos problemas de saúde poderá ter sobre o "encontro clínico", isto é, a consulta que reúne um paciente com um médico ou qualquer profissional da área da Saúde (enfermeiro, fisioterapeuta, psicólogo, etc.). Os autores declaram estar preparando a base para “uma genuína discussão transdisciplinar” que envolva, não apenas profissionais da saúde e filósofos, mas se estenda a pacientes e tomadores de decisão, sendo seu principal propósito "comprometer e empoderar" os profissionais para 
participar da modificação da sua própria prática. E, para tanto, declaram importante compreender que, se a prática deve estar baseada em evidências, elas devem ser "relevantes e bem adequadas à clínica” (e não só cientificamente rigorosas).

Os autores abordam depois um tema bem conhecido na filosofia da ciência: o contraste entre a universalidade dos objetos científicos e a particularidade das coisas e eventos reais. Com efeito, a Ciência não investiga este ou aquele ser individual (seja ele um organismo, um fenômeno atmosférico seja um movimento social) em sua condição de tal, mas no que ele tem em comum com os de sua mesma espécie ou tipo. $\mathrm{O}$ conhecimento do comum ou geral permite explicar o comportamento do individual. Isso vale especialmente para o conceito de "causa" (usado para explicar) e o princípio, essencial na Ciência, de que os mesmos efeitos supóem as mesmas causas.

O texto lembra que a noção de causalidade geralmente usada na Biologia e na Medicina provém da tradição empirista e positivista em Filosofia, uma tradição que remonta ao filósofo escocês David Hume (século 18) e que identifica a causalidade com a correlação constante entre fenômenos observados. É importante reparar que, para essa tradição filosófica, nosso conhecimento não é capaz de superar o âmbito daquilo que é percebido pelos sentidos, de tal modo que, ao considerar a noção de causa, por exemplo, nada podemos dizer de um suposto mecanismo de produção dos efeitos que estivesse além do que a experiência nos mostra. Uma consequência dessa maneira de entender a causalidade consiste em negar que possa haver causalidades únicas. Isso porque o que entendemos por relação causa-efeito é um conhecimento obtido mediante observações repetidas cujo resultado é generalizado (pelo processo denominado de indução) e elaborado mediante a estatística, resultando em conclusões sobre probabilidades. Essas últimas podem, por sua vez, ser entendidas objetiva ou subjetivamente, isto é, como frequências reais ou como graus de confiança que se pode ter em um resultado. Essas conclusões são aplicadas aos indivíduos (pacientes) que representam "casos" da correlação já estabelecida. Note-se que, a rigor, nessa concepção da causalidade nada se sabe sobre a índole ou sua natureza, mas apenas sobre a frequência com que certos efeitos seguem de certas causas ("frequentismo", na denominação dos autores).

Ora, os indivíduos são sempre diferentes uns dos outros, lembram os autores. Isso não importa tanto na explicação científica, porque ela não aspira dar conta dos objetos reais em todos seus aspectos, mas apenas em alguns deles (por exemplo, suas propriedades fúsicas). Mas na Medicina e no cuidado da saúde em geral, os casos individuais (as pessoas e seu adoecimento e tratamento singulares) são o que importa; a sua circunstância é única e desafia tratamentos baseados apenas no que vale "para todos", entre outros motivos, porque às vezes o paciente parece manifestar o efeito de uma causa única. Por essa razão, os autores do livro contrapóem, ao conceito empirista de causalidade (como relação constante) e ao conceito de causa provável, um outro conceito proposto por filósofos contemporâneos: a causalidade entendida como disposição.

O "disposicionalismo" ou "singularismo causal" é a doutrina conforme a qual os "poderes causais" são o que alguma coisa pode fazer (tal como uma faca pode cortar, ou um vírus pode infectar). "Uma disposição - explicam os autores - é um tipo de

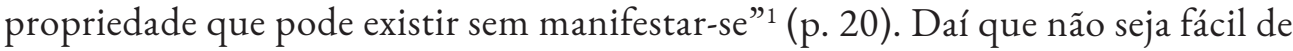
observar até que se manifeste. No entanto, as disposições devem ser reais para produzir seus efeitos. Embora nem todos os filósofos as aceitem, as disposições são importantes em nossa vida, argumentam. "Somos cuidadosos com substâncias explosivas, inflamáveis ou 
venenosas, e não nos expomos desnecessariamente a doenças contagiosas nem deixamos nossos filhos brincarem com facas afiadas” ${ }^{1}$ (p. 21), ilustram. No domínio da clínica, a aplicação da doutrina não é difícil: a observação de pulmôes de um fumante nos mostra que eles têm disposição para um enfisema, uma bronquite crônica ou para o câncer, assim como artérias obstruídas indicam disposição para um ataque cardíaco.

A defesa da doutrina das disposições envolve a convicção de que elas são múltiplas em um caso particular. A causalidade, vista desse modo, é sempre complexa e sensível ao contexto. Por isso: "ao escolher um tratamento para um determinado paciente, deveríamos averiguar mais acerca das disposições do paciente que estará interagindo com o tratamento, assim como acerca das disposições do próprio tratamento"1 (p. 21). Os autores sugerem que uma análise das disposiçôes causais em um paciente específico pode ser realizada por uma modelagem vetorial, em que por meio de uma situação atual são representados vetores de distintas naturezas (disposiçóes causais) e intensidades (como se fossem forças) que apontam em direção do adoecimento (mais sintomas, limitações etc.) ou na direção da cura e do bem-estar (tal modelagem é aplicada em capítulos que relatam e discutem histórias clínicas).

A eficácia de uma intervenção poderá depender não apenas da história médica, mas também da genética, da dieta, da situação de vida e da biografia do paciente. É por isso que essa abordagem inclui sempre o conhecimento da história do cliente, a personalização do diagnóstico. E o mais importante: não basta conhecer a correlação constatada entre determinados sintomas e determinadas causas. É necessário conhecer o mecanismo de produção dos efeitos. Sem esse conhecimento é difícil predizer como um tratamento vai afetar uma pessoa e seu conjunto único de disposiçôes. Por todo o anterior, compreende-se que uma causa tende a produzir diferentes efeitos conforme o contexto. Além do mais, as propensôes de um paciente nem sempre são detectadas pela informação sobre frequências (estatísticas, medicina baseada em evidência).

Na sequência, o livro extrai algumas conclusóes para a prática clínica, como as de que a evidência causal provém do paciente; de que não existe, a rigor, um paciente-padrão ou "em média" (average); e a de que resultados inesperados são valiosas liçóes causais. Em resumo, para os autores a teoria disposicional da causalidade está em melhores condiçóes para servir a uma medicina (e afins) centrada no paciente. Isso não quer dizer, alertam os autores, que os dados resultantes das correlaçóes gerais não sejam úteis: eles podem e devem ser levados em consideração com a devida cautela. As probabilidades, em particular, devem ser entendidas como disposicionais e intrínsecas, ou seja, como "propensóes". No entanto, sem indagar pelo complexo de disposiçóes operantes no caso particular, o tratamento corre o risco de não dar certo.

As consideraçóes precedentes têm por objeto reforçar a ideia-mestra do livro: que as convicçôes ontológicas e epistemológicas governam a maneira de conceber o tratamento adequado. Ao defender o enfoque disposicional, que frisa a importância das propensóes do paciente, os autores salientam a importância que é atribuída ao conhecimento local, bem como à experiência do profissional da saúde, mais do que ao conhecimento de meros valores e parâmetros. De resto, o encontro clínico assim entendido é fonte de novas hipóteses e do progresso da Ciência. Esse encontro não se reduz ao exame do paciente, pois ele é entendido como uma pessoa com uma biografia, um contexto e uma história únicos. Aliás, é característico do encontro prestar atenção à versão e à interpretação que 
o paciente faz da sua situação, em vez de percebê-lo (como no modelo biomédico ainda dominante) como um organismo em que se pode detectar sinais que serão comparados com as evidências estatísticas sobre causas de doenças.

O encontro é uma abordagem tipicamente qualitativa, em que o profissional "coleta muitos tipos de informação em poucos itens, e busca uma compreensão teórica de como se relacionam causalmente em um dado contexto"1 (p. 63), (em vez de) "buscar poucos tipos de informação em muitos índices, para correlacioná-los numericamente” (p. 63), como em um enfoque quantitativo. $\mathrm{O}$ enfoque disposicional pressupóe que todo caso é complexo, mas não no sentido de que sua compreensão advirá de um adequado conhecimento das partes mecanicamente coordenadas que não se transformam devido à interação mútua, como as peças de um carro, por exemplo (a chamada complexidade "mereológica"). A "complexidade genuína” é aquela em que as partes não apenas compóem a totalidade, mas interagem e mudam umas às outras nessa interação, produzindo algo novo (concepção "holística" e "emergente"). É por isso que o enfoque aqui recomendado requer mais de um método para estabelecer as causas de um quadro patológico. O enfoque disposicional ("ecológico", pela atenção dada ao contexto) é particularmente útil - argumentam os autores - nos casos de sintomas não explicados pela Medicina (mais frequentes do que se supóe).

Os autores aplicam seu enfoque disposicionalista e de complexidade genuína na consideração do problema criado pelos guidelines ou diretrizes clínicas (no capítulo 6), cuja importância foi ampliada e transformada pela MBE. O problema decorre de uma contradição irresolvível e incontornável entre uma consensual necessidade de centrar o cuidado clínico nos pacientes e a tendência da MBE de padronização, homogeneização e universalização de tratamentos voltados a doenças, sintomas marcadores biológicos ou aspectos fisiopatológicos; que tendem a afastar a abordagem clínica da complexidade genuína da situação de vida e das características do doente, dificultando ainda mais o cuidado centrado na pessoa.

A ascensão da MBE na década de 1990 gerou importante movimento na Medicina e nos sistemas de saúde. A sistematização das evidências produzidas nos ensaios clínicos foi vista como chance de melhoria da qualidade da clínica (enriquecida com evidências atualizadas) e de maior uniformização dessa qualidade, muito heterogênea. A síntese dessas evidências gerou os guidelines, considerados um padrão ouro terapêutico, e isso teve como efeito certa desresponsabilização de gestores e dos clínicos sobre decisôes (institucionais e terapêuticas), as quais passaram a ser remetidas às evidências científicas (supostamente objetivas e imparciais), condensadas nos guidelines.

Como os guidelines são centrados em doenças e sintomas de pacientes "médios” (por meio da abordagem frequentista dos ensaios clínicos), desconsideram a complexidade genuína das situaçôes e disposiçôes (genéticas, existenciais, psíquicas, ambientais, alimentares e socioeconômicas) dos pacientes singulares. Dessa discussão os autores propóem que os guidelines sejam considerados não como "trilhos de trem", que restringem a liberdade e a responsabilidade do profissional, mas sim como orientaçóes que fornecem informação sobre certas disposiçôes comuns detectadas nos ensaios clínicos, que interagem de forma complexa com outras, possíveis de apreensão via relato da pessoa sobre sua história, experiência de vida e de adoecimento, no encontro clínico. Assim, os profissionais podem ou não usar guidelines, conforme considerarem mais adequado à realidade complexa genuína de cada paciente. Outra consequência de uma 
compreensão disposicionalista dos guidelines é que eles deveriam se tornar bases de dados abertas ao feedback dos clínicos, permitindo seu aperfeiçoamento por meio da clínica, ficando mais maleáveis e nuançados, como ferramentas úteis aos profissionais e não regras padronizadoras para prescrição e execução dos tratamentos.

Os capítulos 7, 8 e 9 transitam da discussão filosófica, ontológica, epistemológica e genérica para a prática clínica. O capítulo 7 discute um caso de dor crônica analisado disposicionalmente (usando modelagem vetorial e mapa conceitual, sugeridos para facilitar o entendimento da complexidade e do singularismo causal pelo clínico e pelo paciente). O seguinte avança na discussão das abordagens dos problemas músculo-esqueléticos e o 9 discute implicaçóes do disposicionalismo para a discussão das causas, do processo diagnóstico e decisório e da relação clínica, com dicas práticas.

O capítulo 10 discute o manejo de pacientes gravemente obesos (algumas histórias são sintetizadas). Destaca a importância das histórias de vida e dos traumas e estresses da vida pregressa e especialmente infantil para o desenvolvimento de problemas crônicos como obesidade excessiva. Essa relevância para a obesidade e outros problemas crônicos "físicos" e "psíquicos" (para esses últimos parece óbvio) foi antigamente reconhecida, mas tem sido muito negligenciada, como ilustra um tratamento psiquiátrico descrito e discutido no capítulo 15. A abordagem de aspectos emocionais e existenciais avança no capítulo 11, que discute valores na relação clínica por uma abordagem fenomenológica derivada da psicologia da Gestalt, convergente com o disposicionalismo.

O capítulo 12 discute os problemas da abordagem baseada em evidências na Saúde Mental e as implicaçôes do disposicionalismo para a pesquisa e a clínica nessa área, defendendo a necessidade de transição do empirismo humeano para o disposicionalismo, o qual ajuda a perceber as limitações das abordagens de pesquisa e psicoterápicas baseadas em evidências; e oferece base filosófica para a construção de hipóteses causais e abordagens terapêuticas sensíveis à complexidade do cuidado das pessoas inteiras.

No capítulo 13, o livro retoma o diálogo com a MBE, oferecendo uma resposta disposicionalista aos três requisitos humeanos para a causalidade - conjunção de causa e efeito, prioridade temporal (causa antes do efeito) e contiguidade (interação íntima entre causa e efeito) -, por meio de quatro critérios disposicionalistas para uma boa explicação causal: " 1 - explicar o papel causal do conteúdo por métodos de pesquisa específicos; 2- motivar uma epistemologia viável; 3- levar em conta os processos causais na tomada de decisão clínica em nível individual; 4- ajudar a compreender e avaliar premissas e suposiçôes adicionais necessárias para preencher a lacuna inferencial entre a evidência no nível da população e as decisões clínicas”' (p. 207). O capítulo compara didaticamente diferenças ontológicas entre a abordagem disposicionalista e a $\mathrm{MBE}$ com base na dor lombar, frequentíssimo problema na população.

O capítulo 14 apresenta a trajetória e a experiência profissional de um médico e psicoterapeuta disposicionalista que desenvolveu uma abordagem chamada "cuidado centrado na pessoa inteira” (Whole Person-Centred Healthcare), visando superar a divisão mente-corpo. O capítulo é ilustrado com a história de uma paciente com doença de pele grave e discute as conexôes entre aspectos simbólicos, sofrimentos somáticos (doenças), narrativas e histórias dos pacientes, visando uma psicoterapia que inclua o corpo e uma clínica que inclua a mente, as emoçôes, a cultura e a história biográfica. 
No capítulo 16 e final, uma síntese propositiva voltada para a prática é oferecida aos clínicos (supondo que leram o livro), com conselhos e dicas práticas, além de alguns comentários sintéticos conceituais, filosóficos e metodológicos centrais e importantes, detalhados e explicados ao longo do livro.

Estamos certos de que o livro será lido com proveito por todos os profissionais da saúde interessados em um cuidado personalizado das pessoas que os consultam, tão caro às discussões da Saúde Coletiva e da Medicina de Família e Comunidade sobre humanização do cuidado, clínica ampliada, projeto terapêutico singular, método clínico centrado na pessoa etc. Ele ajudará no desenvolvimento de abordagens clínicas mais sensíveis aos problemas contextuais e às características singulares dos pacientes, tanto no ensino como na educação permanente dos profissionais em atividade.

\author{
Afiliaçãos \\ (b) Departamento de Saúde Pública, Centro de Ciências da Saúde, Universidade \\ Federal de Santa Catarina (UFSC). Florianópolis, SC, Brasil.
}

\title{
Contribuições dos autores
}

Todos os autores participaram ativamente de todas as etapas de elaboração do manuscrito.

\section{Financiamento}

Charles Dalcanale Tesser recebeu subsídio do CNPq - bolsa de prod. em pesquisa (proc. 303999/2018-7)

\section{Conflito de interesse}

Os autores não têm conflito de interesse a declarar.

\section{Direitos autorais}

Este artigo está licenciado sob a Licença Internacional Creative Commons 4.0, tipo BY (https://creativecommons.org/licenses/by/4.0/deed.pt_BR).

\section{(cc) BY}

\section{Editor}

Antonio Pithon Cyrino

Submetido em

09/02/21.

Aprovado em

$12 / 02 / 21$. 
(c)

\section{Referências}

1. Anjum RL, Copeland S, Rocca E. Rethinking causality, complexity and evidence for the unique patient: a causehealth resource for healthcare professionals and the clinical encounter. Cham, Switzerland: Springer; 2020. https://doi.org/10.1007/978-3-030$41239-5$ 